\title{
Chateaubriand oder die Romantik in der Neuen Welt
}

Wir setzen nun wieder im Bereich der französischen Literatur unsere Suche nach jenen Bildern und Projektionen fort, die von Europa aus und von europäischen Autorinnen und Autoren auf die Neue Welt projiziert wurden und jenes Amerika, das an der Schwelle zu seiner Unabhängigkeitsrevolution stand, auf intensive Weise im Zeichen der Romantik umdeuteten. Auf diese Problematiken einer Suche und der Fragen nach den Projektionen soll uns jener Mann eine Antwort geben, der wohl wie kein anderer in Frankreich stellvertretend für ein Projekt stand, das politisch der Restauration zuzurechnen ist. Auf der anderen Seite aber trieb dieser Autor jene revolutionäre Ästhetik voran und setzte sie durch, die wir unter dem Namen des „Romantisme“, also der Romantik zu kennen glauben. Ich spreche vom Autor des Génie du Christianisme, von Atala und René, der noch in seinen Memoiren wie von der anderen Seite des Grabes her seine Zeitgenossen an dem von ihm konzipierten Weg festzuhalten gemahnte und bis zu seinem Ende eine mit der Französischen Revolution verknüpfte Moderne dezidiert ablehnte: François-René de Chateaubriand. Beschäftigen wir uns zunächst mit einigen Biographemen aus seinem ereignisreichen Leben!

François-René, Chevalier und später Vicomte de Chateaubriand wurde am 4. September 1768 in Saint-Malo geboren und starb am 4. Juli des Revolutionsjahres 1848 in Paris, übrigens in den Armen seiner treuen Freundin Juliette Récamier. Er machte sich nicht nur als einer der Begründer der Romantik in Frankreich einen Namen, sondern auch als hartnäckiger Politiker und geschickter Diplomat, der die Interessen seines Landes eisern auf allen europäischen Bühnen verteidigte, letztlich aber grummelnd und grollend aus der Politik schied.

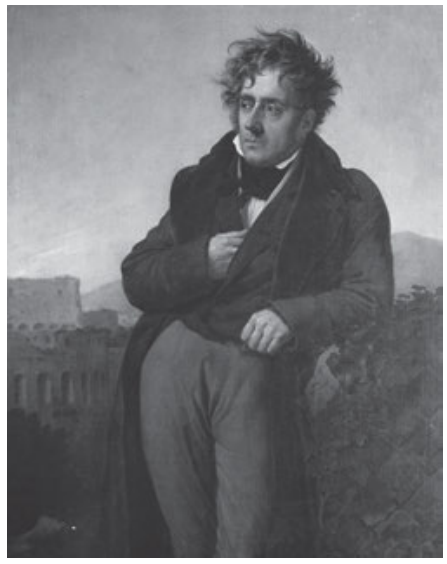

Abb. 16: François-René de Chateaubriand (Saint-Malo, 1768 - Paris, 1848). 
Als jüngstes von nicht weniger als zehn Kindern - bis heute hat der Adel eine hohe Kinderzahl als oberste Regel - wuchs Chateaubriand auf Schloss Combourg in der Bretagne und in Saint-Malo auf, von wo einige der verwegensten Seefahrer Frankreich stammen, die sogar den Malwineninseln vor der argentinischen Küste ihren Namen gaben. Die Jahre seiner Kindheit verbringt er hinter dunklen Schlossgemäuern, umgeben von einem schweigsamen Vater, einer frommen Mutter und einer träumerischen Schwester, tief von dem geprägt, was man das „mal du siècle“ nennen sollte: der Melancholie. Eine Zeit, welche die Chateaubriand'sche Empfindsamkeit stark beeinflussen sollte.

Der junge Chateaubriand sollte nach dem Willen seines Vaters in die Marine eintreten, nach den Wünschen seiner Mutter hingegen Priester werden. So schwankte er - um mit Stendhal zu sprechen - zwischen Rot und Schwarz, zwischen „Le Rouge“ und „Le Noir“, bis er 1786 die Stelle eines Leutnants im Regiment Navarra erhielt. Er wurde, worauf seine adelige Familie ein Recht besaß, dem König vorgestellt und blieb auch später der Bourbonen-Monarchie treu. Bereits aus seinen frühen Jahren sind einige literarische Versuche bekannt; doch es sind noch die Fingerübungen des späteren großen Schriftstellers der französischen Romantik.

Hatte er anfänglich durchaus Sympathien für die Französische Revolution aufgebracht, so war er doch zunehmend enttäuscht vom Verlauf der Ereignisse und verließ 1790 seine Division. Bereits 1791 entschloss er sich zur Emigration und begab sich, versehen mit einem Empfehlungsschreiben an George Washington, auf eine lange Zeit in ihrem Verlauf umstrittene neunmonatige Reise nach Nordamerika, wobei er vor allem die damals noch französischen Gebiete am Mississippi erkundete. Das Erleben der dortigen Natur hinterließ tiefe Spuren bei diesem einfühlsamen Geist: Seine literarisch fein herausgearbeiteten Naturdarstellungen sollten noch seinen reisenden Zeitgenossen Alexander von Humboldt begeistern. Wie weit er freilich bei seiner Reise nach Westen vordrang, ist seit der Veröffentlichung seines Reiseberichts, des Voyage en Amérique, im Jahre 1827 eine heiß diskutierte Frage. Denn für ihn griff er auch auf andere Berichte und Quellen zurück, wobei er sich nicht scheute, unseren Bernardin de Saint-Pierre mit dessen Naturschilderungen aus dem Indischen Ozean auf die Gebiete der Neuen Welt zu übertragen.

Ab dem 2. Februar 1792 war Chateaubriand wieder in Le Havre, heiratete standesgemäß, schloss sich dann aber sehr bald der Armée des Princes an, beziehungsweise der Armée des Emigrés, die - zumeist aus französischen Adeligen bestehend - auf der Seite Österreichs und Preußens gegen die Französische Revolution und für die Wiedereinführung der Monarchie in Frankreich kämpfte. Doch der Kampf war vergebens: 1793 wurde Chateaubriand verwundet und ließ sich nach seiner Genesung in London nieder, wo er sich als Französischlehrer und 
Übersetzer mehr schlecht als recht über Wasser hielt. Nun intensivierte er seine schriftstellerischen Aktivitäten.

Bereits 1784 bis 1790 waren seine frühen Gedichte unter dem Titel Tableaux de la Nature entstanden, die man - wie etwa auch L'amour de la campagne - mit Versidyllen im Stil von James Thomson, Salomon Gessner und Jean Regnault de Segrais verglichen hat. 1797 veröffentlichte er in der britischen Hauptstadt seinen Essai sur les révolutions anciennes et modernes, von dem 1826 eine überarbeitete Fassung samt einer erfundenen Begegnung mit Washington erschien. In diesem Essai versuchte Chateaubriand, die Ereignisse der Revolution, seine Emigration, den Tod vieler Verwandter und Freunde und den ihm nicht genehmen Lauf der Geschichte literarisch wie psychologisch zu verarbeiten. Chateaubriand verlor einen Teil seiner Familie durch die Guillotine, andere Familienmitglieder starben unter üblen Umständen an Entkräftung: Der junge Adelige ist fortan weitgehend auf sich alleine gestellt und wird zeitlebens immer wieder unter Geldnöten leiden.

Die Autoren, die Chateaubriand am meisten bewunderte, waren neben dem ,Klassiker‘ Fénélon Jean-Jacques Rousseau und Bernardin de Saint-Pierre: So knüpft er an eben jene literarischen Vorläufer an, die wir in dieser Vorlesung herausgearbeitet haben. Nach seiner bewussten Hinwendung zum christlichen Glauben verband er die Vorstellungen beider Schriftsteller mit einer Apologie des Christentums, ${ }^{1}$ die mit einer dezidiert anti-aufklärerischen Stoßrichtung schließlich 1802 in Gestalt von Le Génie du Christianisme erschien. Von diesem Werk gingen - nicht zuletzt unter dem Eindruck des Schicksals seiner Familie Versuche einer Rehabilitierung des Christentums und wesentliche Impulse für eine gegen die Aufklärung gerichtete Strömung der französischen Romantik aus. Auch wenn Chateaubriand gewisse opportunistische Gründe dafür gehabt haben dürfte, sich in einer Zeit, in welcher Napoleon sich vermehrt um die Gunst der Kirche bemühte, für letztere einzusetzen, so ist die grundlegende ästhetische Aufwertung der christlichen Religion doch ein genuines politisches wie literarisches Anliegen des nach Frankreich zurückgekehrten und in den romantischen Zirkeln der französischen Hauptstadt verkehrenden Adeligen. In der Tat sollte Napoleon gegen die Aufklärung gerichtete und mit der katholischen Kirche versöhnende Tendenzen dieses Werkes fördern und dessen Verfasser anfänglich unterstützen.

Wie Bernardin de Saint-Pierre ursprünglich in seine Etudes de la Nature den kleinen Roman Paul et Virginie eingefügt hatte, so flocht auch Chateaubriand in Le Génie du Christianisme zwei kürzere Erzähltexte ein. Der erste wurde bereits

1 Vgl. hierzu auch Grimm, Reinhold R.: Romantisches Christentum. Chateaubriands nachrevolutionäre Apologie der Revolution. In: Maurer, Karl / Wehle, Winfried (Hg.): Romantik. Aufbruch zur Moderne. München: Fink 1991, S. 13-72. 
1801 unter dem Titel Atala separat gedruckt und erlebte noch im ersten Jahr fünf Auflagen. Es handelt sich um ein Werk, das zusammen mit René einen wahren Kultstatus in der zeitgenössischen französischen Literatur erlangte. Die weibliche Titelheldin wie der männliche Protagonist wurden zu Ikonen einer ästhetischen Selbstvergewisserung Frankreichs, die in ihrer literarischen Ausgestaltung durchaus radikal Neues, in ihrer politischen Stoßrichtung durchaus Konservatives beförderten. Diesen Fragen werden wir uns nachfolgend aber noch ausführlicher widmen, wollen aber an dieser Stelle bereits festhalten, dass ebenso Atala wie René eine große literarische Nachkommenschaft - wohlgemerkt: in beiden Welten - haben sollten.

Im Jahr 1803 wurde Chateaubriand unter Napoleon in Rom Botschaftssekretär und danach andernorts zum Botschafter ernannt. Doch zum Antritt der Stelle kam es nicht mehr: Im Jahr 1804, nach der Entführung und Erschießung des potentiellen Thronfolgers und Herzogs von Enghien, brach Chateaubriand ostentativ mit dem selbsternannten französischen Kaiser. Nur scheinbar zog er sich in der Folge in sein Privatleben zurück. 1806 unternahm er - wie nach ihm Gustave Flaubert - eine mehrmonatige, von keinem Geringeren als Edward Said als ,orientalistisch' bezeichnete Rundreise über Italien und das damals noch besetzte Griechenland nach Palästina - wo er einigen Quellen zufolge in Jerusalem zum „Ritter vom Heiligen Grab“ geschlagen wurde -, nach Nordafrika und zurück über Spanien wieder nach Frankreich. Für die Wahl der Route über die iberische Halbinsel waren wohl auch Liebesbeziehungen entscheidend, die im Umfeld des Schriftstellers immer rasch entstanden und wieder vergingen.

Erst 1811 veröffentlichte er seinen Itinéraire de Paris à Jérusalem, der ebenso erfolgreich war wie sein später veröffentlichter Reisebericht Voyage en Italie. Chateaubriand war ein hochbegabter Reiseschriftsteller, was ihn mit seinem Vorbild Bernardin de Saint-Pierre verband. Immer wieder bearbeitete er das große Thema der unglücklichen Liebe, womit er etwa in Les aventures du dernier Abencérage in fremdländischem Dekor die eigenen scheiternden Liebesverhältnisse verarbeitete. Vielleicht war in all diesen amourösen Wirren allein seine Freundschaft und Liebe zu Madame Récamier, mit der er auch die Liebe zur Literatur teilte, über die Jahrzehnte konstant. Seine endgültige Kanonisierung als großer Schriftsteller erlebte er 1811 durch seine Aufnahme in die „Akademie der Unsterblichen“ - die Académie française - auch wenn er sich weigerte, seine von der napoleonischen Zensur verstümmelte Rede öffentlich vorzutragen.

Fassen wir das weitere Leben des arrivierten Chateaubriand in der gebotenen Kürze zusammen, so können wir in ihm einen typischen Vertreter der monarchistischen Restauration erkennen. In nachnapoleonischer Zeit wurde er 1821 Gesandter in Berlin, 1822 in London und 1828 in Rom, wo er 25 Jahre früher bereits Botschaftssekretär gewesen war. Die Monarchie dankte Chateaubriand für dessen 
ultraroyalistische Positionen mit zahlreichen Ehrungen und Ernennungen, auch wenn er als kurzfristiger Außenminister der Regierung von Charles X. bald wieder entlassen wurde. Nach seinem außenpolitischen Erfolg, in Spanien die liberalen Tendenzen durch eine französische Militärintervention unterdrückt zu haben, prägte er anderthalb Jahrzehnte lang das Gesicht des restaurativen Frankreich. Er war als französischer Politiker und Diplomat eine Europa neu, aber restaurativ ordnende Figur, die 1821 eine präponderante Rolle beim Kongress von Verona spielte. Er betätigte sich in dieser Zeit seltener literarisch, trat aber 1818 bis 1820 als Herausgeber der Zeitschrift Le Conservateur hervor und beschäftigte sich mit der Abfassung seiner Memoiren. Diese jahrzehntelange, freilich immer wieder unterbrochene Arbeit führte schließlich zur Veröffentlichung seiner Mémoires d'outre-tombe, die sein großes Alterswerk darstellen und ein zeitgeschichtliches Panorama des damaligen Europa bieten. Zahlreiche politische Schriften aus seiner Feder erschienen, doch können wir uns im Rahmen unserer Vorlesung damit leider nicht beschäftigen. In seinen gegenüber den Bourbonen treuen und ultraroyalistischen Auffassungen blieb sich Chateaubriand bis zum Tode selbst treu.

Anlässlich der Premiere von Victor Hugos Stück Hernani gratulierte er dem jungen Dichter, der nach eigener Aussage „Chateaubriand oder nichts“ werden wollte, und verstand, dass nun andere Stimmen die Führung der romantischen Bewegung in Frankreich übernehmen würden. Doch sein literarisches Erbe wollte er sichern: Verschiedene Ausgaben seiner Euvres Complètes erschienen. Den weiteren Entwicklungen in der europäischen Romantik stand er distanziert, bisweilen mit bissiger Kritik gegenüber. Für ihn verband sich die Idee jeglicher Kultur mit dem Christentum, jene Vorstellung, die mit Le Génie du Christianisme für seinen Aufstieg gesorgt hatte und an der er zeit seines Lebens festhielt. Bis zu seinem Lebensende warf er selbst konservativen Historikern, die von der Notwendigkeit der Französischen Revolution sprachen, unerschütterlich ein falsches Denken vor, war nach seinem Dafürhalten die Revolution von 1789 doch nur ein Versehen der Geschichte gewesen, das man leicht hätte ausmerzen können. Als die Julirevolution von 1830 die Bourbonen verdrängte und der sogenannte ,Bürgerkönig‘ Louis-Philippe die Macht übernahm, zog sich Chateaubriand grollend aus der Politik genauso zurück, wie er dies auch aus der zeitgenössischen romantischen Bewegung tat. Doch noch war sein literarischer Nachlass nicht gesichert.

Jenseits aller anderen noch von ihm verfassten historiographischen oder literarhistorischen Schriften arbeitete er beständig an seinen Mémoires d'outretombe, deren Rechte er bereits in den dreißiger Jahren verkauft hatte und die vertragsgemäß erst nach seinem Tode erschienen. Der Verkauf dieser Rechte sicherte ihm ein auskömmliches Alter. 1842 wurde er in den von Alexander von Humboldt initiierten Orden Pour le Mérite aufgenommen, offenkundig unter Zutun des preu- 
Bischen Reiseschriftstellers und Naturforschers, der Chateaubriands Schilderung der Naturszenen in jenen Jahren in seinem Kosmos ein literarisches Denkmal setzte. Nachdem er noch die Februarrevolution von 1848 und die Niederschlagung der Pariser Arbeiterrevolte im Juni seines letzten Sommers miterlebt hatte, verstarb der an Gicht und anderen Gebrechen erkrankte Schriftsteller am 4. Juli 1848 wohl in den Armen von Madame Récamier und wurde - seinem Wunsch entsprechend - auf der Insel Grand-Bé unweit seines Geburtsortes Saint-Malo bestattet.

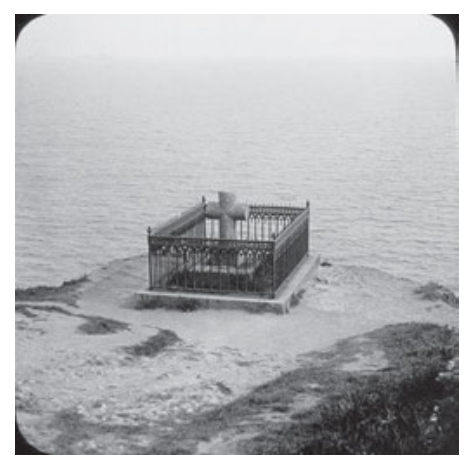

Abb. 17: Grabmal von François-René de Chateaubriand, auf dem Felsen Grand Bé, Saint-Malo.

Doch gehen wir nun fast fünf Jahrzehnte an den Beginn des 19. Jahrhunderts zurück! Mit seinem Roman Atala ou les amours de deux sauvages dans le désert hat Chateaubriand zweifellos eines der großen, prägenden Werke der französischen Romantik beziehungsweise der Frühromantik geschaffen. Der im Jahr 1801 erstmals separat erschienene Text wurde wenige Jahre später zusammen mit René in Chateaubriands Le Génie du Christianisme integriert. Dergestalt erhielt er eine funktionale Bedeutung innerhalb dieser Religionsschrift, die sich zum einen als die Apologie des Christentums schlechthin lesen lässt, zum anderen aber auch eine Ästhetisierung des Christentums darstellt. Sie entzieht dieser Religion gerade ihre dogmatischen und kirchenrechtlichen Grundlagen und bereitet auf diese Weise einer romantischen Ästhetik den Weg. Denn es ging um Christentum oder Katholizismus nicht als theologische oder religiöse Formationen, sondern vielmehr als Kultur schaffende und gestaltende Kräfte, welche der modernen abendländischen Zivilisation als Grundlage dienten. Der Text wurde rasch nicht nur innerhalb Frankreichs, sondern - wie wir noch sehen werden - auch weit jenseits der Grenzen Europas zu einem Bezugstext, der das Lebensgefühl zumindest einer Epoche und mehrerer Generationen auf beiden Seiten des Atlantik ganz entscheidend mitprägte.

Die Geschichte ist auf Ebene der „histoire“ in aller Kürze schnell erzählt. Wir hatten ja bereits gesehen, dass der junge Chateaubriand unter anderem in 
die Regionen am Mississippi gereist war; und in diesem tropisch untersetzten Landschaftsbereich situiert sich auch sein kurzer, aber einflussreicher Erzähltext. In seinem Aufbau knüpft er unverkennbar an die narrative Gestaltung von Bernardin de Saint-Pierres Paul et Virginie an. Der greise und im Übrigen blinde Indianerhäuptling Chactas - seine Blindheit gemahnt nicht von ungefähr an den greisen Ödipus - erzählt seinem Adoptivsohn René, einem jungen nach Amerika ins Exil gegangenen Franzosen (und vergessen wir nicht, dass René der zweite Vorname unseres Autors ist), seine insgesamt betrübliche Lebensgeschichte. Wir stoßen also auf dieselbe Struktur von Rahmen- und Binnenerzählung, die wir von Bernardin de Saint-Pierre her bereits kennen.

Diese Lebensgeschichte ist geprägt von seiner schicksalhaften Begegnung mit der selbstverständlich wunderschönen Atala, Tochter eines Weißen und einer Indianerin. Anders als bei Heinrich von Kleists schöner Toni handelt es sich bei ihr also um eine wirkliche Mestizin. Chactas berichtet von ihrem Kennenlernen, ihrer gemeinsamen Flucht, den unschuldig-glücklichen Tagen in den Savannen und dem jähen Ende ihres gemeinsamen Glücks und all ihrer Hoffnungen. Gewiss liebte die blonde und mit einem Kreuz geschmückte Christin Atala den ,wilden', den Göttern seiner Hütte noch immer getreuen Chactas, doch ist sie auf Grund eines Schwures ihrer Mutter der Heiligen Jungfrau versprochen und entzieht sich schließlich der Entscheidung zwischen einem frommen, keuschen und einem natürlichen, freien Leben, indem sie in ihrer Verzweiflung Selbstmord begeht. Auch in diesem Kurzroman geht alles folglich nur über die Leiche der jungen und schönen Frau.

Ich möchte Ihnen gerne an dieser Stelle zunächst - passend zu unseren Überlegungen, die wir im Zusammenhang mit Paul et Virginie angestellt hatten - eine Passage vorstellen, die oftmals zum Gegenstand von Darstellungen in der Malerei geworden ist: Es handelt sich um die erste Begegnung zwischen jenen beiden „sauvages“, jenen beiden ,Wilden“, die sich nun inmitten der Savannen-Wüste so herrlich finden, dass sie voneinander nicht lassen können. Es erzählt Ihnen also der greise Chactas, vermittelt durch den Zuhörer René, die Szene in einer von nomadisierenden Indianern durchzogenen, aber letztlich menschenleeren Gegend (und genau das ist mit dem französischen Wörtchen „désert“ gemeint):

In einer Nacht, in der die Muskogulgen ihr Lager am Rande eines Urwaldes platziert hatten, saß ich in der Nähe eines Kriegsfeuers zusammen mit dem Jäger, der mit meiner Bewachung betraut war. Plötzlich hörte ich das Rascheln eines Kleidungsstückes auf dem Gras, und eine halb verschleierte Frau erschien, um sich an meine Seite zu setzen. Ein Weinen zuckte um ihre Lider; im Lichte des Feuers glänzte ein kleines goldenes Kruzifix auf ihrem Busen. Sie war sehr schön; auf ihrem Gesicht bemerkte man ich weiß nicht welche Tugendhaftigkeit und Leidenschaftlichkeit, deren Anziehungskraft unwiderstehlich war. Hinzu kamen die 
Zeichen einer noch zärtlicheren Anmut; eine extreme Empfindsamkeit, die mit einer tiefen Melancholie einherging, lebte in ihren Blicken; ihr Lächeln war himmlisch.

Ich dachte, es wäre die Jungfrau der letzten Liebe, jene Jungfrau, die man dem Kriegsgefangenen schickt, um noch sein Grab zu verschönen. ${ }^{2}$

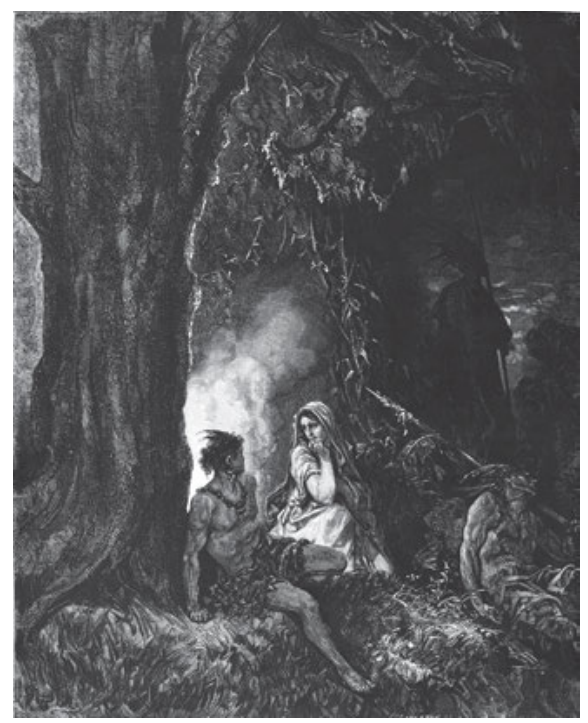

Abb. 18: „Die Begegnung mit Atala“, Gravur von Gustave Doré, 1863.

In diesem literarischen Portrait der jungen Atala, die wir uns blond und barbusig vorstellen müssen, freilich mit einem großen christlichen Kreuz, das ihre Brüste gleichsam vor den Blicken der Männer schützt, stoßen wir auf eine Vielzahl von Elementen, die wir bereits zumindest ansatzweise in unserer Vorlesung kennengelernt haben. Da ist zum einen die Präsenz der unvergleichlichen Frau, die wir schon in Paul et Virginie in einem exotischen Ambiente kennenlernen durften, auch hier wiederum mit etwas Engelhaftem, zumindest aber Himmlischem gepaart. Wie Virginie gehört auch die blonde Mestizin Atala zum Reservoir der himmlischen, engelhaften, jungfräulichen Heldinnen, die sich letztlich den Männern immer durch ihren Tod entziehen. Sie verkörpern die Unerreichbarkeit des Liebesobjekts, ja die Unerreichbarkeit der menschlichen Liebe überhaupt. War Virginie am Ende den nassen, kalten Tod gestorben, wobei ihre heldenhafte Keuschheit sich auch als Negation gegenüber dem Leben lesen lässt, so stirbt

2 Chateaubriand, François-René vicomte de: Atala; René; Les Abencérages; Suivies de Voyage en Amérique. Paris: Librairie de Firmin Didot frères 1871, S. 30. 
Atala den Freitod, der die christliche Frau nicht weniger effizient, wenn auch der katholischen Lehre nicht entsprechend, den begehrlichen Blicken - und mehr als nur diesen - der Männer entzieht.

Da ist des Weiteren das Element des Schleiers, das wir im Zusammenhang mit Jean-Jacques Rousseau bereits besprochen haben, und das hier sowohl den Blicken etwas freigibt und entblößt und zugleich doch wieder entzieht. Es ist jenes Wechselspiel zwischen der „transparence“ und dem „obstacle“, zwischen der Sichtbarmachung und dem Widerstand, das wir in Jean Starobinskis klassischer Studie bereits bemerken konnten. ${ }^{3}$ Atala erweist sich in diesem Spannungsfeld als Heldin des Zwischen- oder Grenzbereichs. Und dies verwundert uns nicht, erfahren wir doch später, dass sie die Tochter eines Weißen und einer Indianerin ist, also auf halbem Wege zwischen Europa (oder doch zumindest den Kreolen) und der amerindischen Bevölkerung steht. Wieder also handelt es sich um eine Frauengestalt, die sich in einem Zwischenbereich ansiedelt, ganz so, wie wir dies bei Toni in Kleists Die Verlobung in St. Domingo gesehen hatten. Ob Mulattin oder Mestizin: Stets bewegt sich die angebetete Frau in einem Spannungsfeld, das von ihrer ethnischen Herkunft nur angedeutet wird und weit über die (rassistische) Frage nach der Hautfarbe hinausgeht.

Es kommen aber auch eine Reihe neuer Elemente hinzu, von denen das eine die Melancholie nämlich - bereits massiv in Paul et Virginie vorhanden gewesen war, ohne dass wir uns darum besonders sorgfältig und aufmerksam gekümmert hätten. In der angeführten Passage aber erscheint es sogleich an die Schönheit und vielleicht mehr noch an die Gestalt der Frau gekettet, auch wenn die Melancholie - wie wir später noch sehen werden - sehr wohl auch Besitz vom Manne ergreifen kann. Und doch ist sie in grundlegender Weise mit der Frau, dem weiblichen Körper, mit einer weiblichen De-Pression verbunden, ein Tatbestand, den Julia Kristeva in Soleil noir sehr schön mehrfach herausgearbeitet hat. ${ }^{4}$ Doch wir werden später zu diesem berüchtigten „mal du siècle“ vorstoßen und ihm ein eigenes Kapitel widmen.

Lassen Sie mich an dieser Stelle zumindest einen kurzen Blick auf den sogenannten Prolog, den ersten Teil von Atala werfen! Er beginnt mit Worten und Wendungen, die wir so oder ähnlich auch in der zeitgenössischen Reiseliteratur wie auch in geographischen Abhandlungen über ferne Länder finden könnten. Die Rede ist bald vom Mississippi, der das beherrschende Landschaftselement dieser exotischen subtropischen Welt darstellt:

3 Vgl. Starobinski, Jean: Jean-Jacques Rousseau. La transparence et l'obstacle. Suivi de Sept Essais sur Rousseau. Paris: Gallimard 1971.

4 Vgl. Kristeva, Julia: Soleil noir. Dépression et mélancolie. Paris: Gallimard 1987. 
Frankreich besaß dereinst in Nordamerika ein weites Reich, das sich von Labrador bis hinunter nach Florida und von den Küsten des Atlantiks bis hinüber zu den entferntesten Seen des oberen Kanada erstreckte.

Vier große Ströme, die ihre Quellen in den selbigen Bergen hatten, teilten diese unermesslichen Regionen auf [...].

Dieser letztgenannte Strom bewässert auf seinem Laufe von mehr als tausend Meilen eine wunderschöne Gegend, welche die Bewohner der Vereinigten Staaten das neue Eden nennen und welcher die Franzosen den süßen Namen Louisiana hinterlassen haben. ${ }^{5}$

Diese einleitende Passage ist in mehrfacher Hinsicht bemerkenswert! Denn stilistisch und inhaltlich ergibt sich eine große Nähe zu geographischen Abhandlungen, die Chateaubriand bei der Abfassung seines Bandes in der Tat auch sehr intensiv las und benutzte. Das angesprochene Zitat zelebriert die frühere Größe Frankreichs und preist im Namen Louisianas die Genealogie der französischen Könige, welche sie repräsentierten. Zugleich wird ein Aspekt des Textes hervorgehoben, den Chateaubriand in seinem Vorwort bereits ansprach, nämlich die Tatsache, dass es sich - wie er meinte - nicht um einen rein fiktionalen Text handele.

Dies ist zutreffend: Atala ist in der Tat eingebaut in Le Génie du Christianisme und damit in einen nicht-fiktionalen Text. So erklärt sich auch der nichtfiktionale Beginn, der gleichsam - um die Begriffe Gérard Genettes zu verwenden ${ }^{6}$ - wie eine Schwelle zwischen dem Bereich der Diktion und der Fiktion liegt. Darüber hinaus wird natürlich auch auf die Bezüglichkeit des nachfolgenden fiktionalen auf den vorangehenden diktionalen Text aufmerksam gemacht und so zugleich nahegelegt, dass Atala gleichsam mit fiktionalen Mitteln jene Thesen erläutern wolle, welche im diktionalen Text langatmig entwickelt wurden. Die Fiktion erlaubt eine gewisse Verdichtung, durchaus im Sinne einer Dichtung, insofern sie unterschiedlichste diskursive Elemente zusammenführt und zusammenrafft. Gleichzeitig gibt sie selbstverständlich die Möglichkeit an die Hand, gleichsam die irrationalen Restbestände, die in einer diskursiven Textsorte nicht so leicht thematisiert und noch weniger angesprochen oder bearbeitet werden können, für die Leserschaft so aufzuarbeiten, dass hierdurch eine Arbeit an den Affekten geleistet werden kann.

Dass der auf den ersten Blick diktionale Beginn von Atala es aber durchaus faustdick hinter den Ohren hat, zeigt sich schon am kleinen, leicht zu übersehenden Textelement der vier Ströme. Denn dieses ist keineswegs „gratuit“, sondern bezieht sich auf eine biblische Vorstellung, die selbstverständlich schon

5 Chateaubriand: Atala, S. $19 \mathrm{f}$.

6 Vgl. Genette, Gérard: Seuils. Paris: Sueil 1987; sowie ders.: Fiction et diction. Paris: Seuil 1991. 
Christoph Kolumbus geläufig war. Denn vier Ströme bewässerten das Irdische Paradies, und einen dieser vier Ströme glaubte der Genuese vor der Mündung des gewaltigen Orinoco erreicht zu haben.

Mit dieser unscheinbaren Wendung knüpft Chateaubriand sehr bewusst an die biblische Vorstellung, aber auch an Kolumbus und dessen Entdeckertradition an. Die zitierte Passage führt mithin zum einen die Dimension des Irdischen Paradieses als textuelles und interpretatives Element ein, das in der Folge entwickelt wird; zum anderen ergibt sich eine autobiographische Dimension, insoweit Chateaubriand - der reale Autor wohlgemerkt - ja in der Tat für sich in Anspruch nahm, eine wirkliche Entdeckerfigur zu sein. Noch in seinem Vorwort zu Atala machte er darauf aufmerksam, für Frankreich nach Amerika gereist zu sein, um die berühmte Nordwestpassage zu finden, jene Durchfahrt also, nach der die Spanier seit dem Ausgang des 15. Jahrhunderts - so etwa auch Kolumbus gesucht hatten. Diese noch bis in die erste Hälfte des 19. Jahrhunderts hinein von den Europäern gesuchte Nordwest-Passage sollte es deren Händlern und Kaufleuten erlauben, den Umweg über die zeitraubende Umschiffung von Kap Hoorn, dem „Cabo de Hornos“, einzusparen und den Weg nach Asien, zu den Gewürzinseln und den Reichtümern des asiatischen Kontinents samt seinen Inselwelten schneller zu finden.

François-René de Chateaubriand sah sich als Entdecker in einer langen Tradition. Noch in der zweiten Hälfte des 18. Jahrhunderts hatten zahlreiche Expeditionen, darunter die des Engländers James Cook und so viele andere französische Entdecker wie Louis-Antoine de Bougainville nach dieser Nordwestpassage, von deren Existenz man lange überzeugt war, fieberhaft gesucht. Man vermutete sie nicht zuletzt im Bereich der großen Flüsse sowie der Großen Seen des Nordens, also entlang des Sankt-Lorenz-Stroms und der Great Lakes. Auch auf der pazifischen Seite glaubte man mehrere Buchten gefunden $\mathrm{zu}$ haben, die ins Innere des Kontinents führten und eine solche Durchfahrt noch immer als möglich erscheinen ließen. In dieser historischen Konstellation wollte Chateaubriand nach eigener Aussage zu einem neuen Kolumbus werden, zu jener großen Figur des europäischen Entdeckers, zu welcher er freilich in einem geographischtopographischen Sinne niemals geworden ist. Seine Berühmtheit sollte sich auf andere Gebiete erstrecken.

Zugleich verbindet sich mit diesen Äußerungen zu Beginn von Chateaubriands Atala ein wehmütiger, fast nostalgischer Rückblick in die Vergangenheit des einstmals gewaltigen Kolonialreichs in Amerika, das die Franzosen freilich zu großen Teilen in den fünfziger Jahren des 18. Jahrhunderts verloren. Es sind diese ruhmreichen Zeiten, an die hier appelliert wird, in denen Frankreich als europäische Kolonial- und Seemacht England noch Paroli bieten konnte. Gleichzeitig handelt es sich um eine Erinnerung des Royalisten und Monarchisten Cha- 
teaubriand an jene süße Epoche, als man ein französisches Kolonialland noch als „Louisiane“ benennen und bezeichnen durfte - dies war jedoch einstweilen verlorene nationale Größe. Doch träumte schon der junge Chateaubriand davon, der ,Grande Nation' wieder zu ihrer einstigen Macht zu verhelfen. Nicht umsonst ging er später mit diesen Vorsätzen in die Politik, im Grunde zeitgleich zur Veröffentlichung von Atala, nach seiner Rückkehr aus dem britischen Exil und den harten Jahren des Sich-Durchschlagens in London. Und diese Jahre schienen ihn nur stärker gemacht zu haben.

All diese Hintergründe und Zusammenhänge lassen es uns als verständlich erscheinen, dass Chateaubriand in seinem Text von Beginn an einen kolonialeuropäischen Blick, eine eurozentrische Perspektive einnahm, welche selbstverständlich auch seinem gesamten Génie du Christianisme die Prägung gab. Denn an der kulturellen Superiorität des Abendlandes war für ihn kein Zweifel möglich: Der junge Schriftsteller, der in den Jahren der Französischen Revolution viele Familienangehörige verloren hatte, betonte die historische und ästhetische Überlegenheit des Christentums, in welchem er die tragende und zentrale Säule der führenden europäischen Gesellschaften und insbesondere Frankreichs erkannte. Diese kulturelle Dominanz galt es wieder weltweit durchzusetzen.

So handelt es sich folglich um einen europäischen Blick auf die Neue Welt, der auf diesen Seiten unverblümt zum Ausdruck kommt. Zugleich war es ein Blick, der laut eines von Chateaubriand später verfassten Vorworts durch die Bewohner der USA selbst bestätigt werde, denn sie hätten von Beginn an Atala einen großen Verkaufserfolg beschert. Wer würde schon einen Text über sein eigenes Land kaufen, in dem dieses nicht zutreffend beschrieben worden wäre? Es ist also ein europäischer Blick, der auf seinem Wahrheitscharakter durch die Rückversicherung mit den des Lesens kundigen Bewohnern der Vereinigten Staaten von Amerika vertraut.

Ich möchte es noch einmal betonen: Die narrative Struktur des kurzen Erzähltextes ist ebenso wie dessen Einbettung in einen diktionalen Kontext sehr eng am Vorbild Bernardin de Saint-Pierres orientiert, dessen Paul et Virginie sich zum damaligen Zeitpunkt glänzender Neuausgaben erfreute. Diese Engführung war den Zeitgenossen Chateaubriands durchaus nicht verborgen geblieben. So konnte es auch nicht verwundern, wenn sich Chateaubriand bei aller Bewunderung später zum Teil allzu spektakulär von seinem Vorgänger absetzen und ihn für einen wahrhaft durchschnittlichen Geist erklären zu müssen glaubte. Tatsache aber bleibt, dass Bernardin de Saint-Pierre - und insbesondere seine präromantischen Protagonisten in Paul et Virginie, für die Konzeption wie die Abfassung von Chateaubriands Atala von entscheidender Bedeutung waren.

Auf diese intertextuelle Beziehung verweist neben vielen anderen Strukturund Textelementen bereits der Untertitel des Kurzromans, Atala ou les amours de 
deux sauvages dans le désert. Nicht nur die kotextuelle, also die im selben Band publizierte Einbettung sowie der Paratext, sondern auch die bewusst gewählte Erzählstruktur von Atala ist eng an Paul et Virginie und dessen fiktionales Erfolgsmodell angelehnt. Wir haben es, wie bereits erwähnt, mit einer Binnenerzählung und einer Rahmenerzählung zu tun, wobei diese Rahmenerzählung offenkundig ihrerseits noch einmal gerahmt wird durch eine zusätzliche Zeitund Raumebene, eine zusätzliche Diegese also, welche auch die zeitliche Verbindung mit der Epoche der Niederschrift des Romans herstellt. Denn wie bei Paul et Virginie kommt ein Greis vor, der eine Figur der Binnenerzählung darstellt; im Unterschied zum Greis Bernardin de Saint-Pierres freilich ist Chateaubriands alter, gebrochener Mann neben der schönen Atala die eigentliche Hauptfigur des gesamten Romans.

Anders als bei Bernardin ist er zudem blind, damit also an die Figur des blinden Sehers bei Homer angelehnt. An Anspielungen auf antike Vorbilder mangelt es in der Tat bei Chateaubriand nicht und wir treffen auf viele Topoi der „Belles-Lettres“: Auch bei Chateaubriand ist das Auge zum Hort der Tränen geworden, auch bei ihm dienen die Augen nicht vorrangig zum Sehen. Vielmehr drehen sie die Informationsrichtung um: Sie geben Aufschluss über das Innere des weinenden Menschen, sind gleichsam die Fenster zu dessen Seele. Der alte Chactas also erzählt sein Leben einem Franzosen namens René, dessen eigene Lebensgeschichte Chateaubriand in einem nicht weniger berühmten Text unter dem Titel René im Zeichen der Melancholie abgehandelt hat.

Chactas ist zum Zeitpunkt seines Erzählens bereits recht alt, und man könnte erschließen, dass er etwa um 1653 geboren sein dürfte. Das Treffen mit dem jüngeren René könnte also im dritten oder vierten Jahrzehnt des 18. Jahrhunderts stattgefunden haben, Chactas wie René sind zum Zeitpunkt der Veröffentlichung des Romans also längst tot. In diesem zeitlich mehrschichtigen Zusammenhang tritt ganz am Ende des Texts ein Ich auf, das von einem umherirrenden Indianerstamm diese Geschichte der längst Verstorbenen gehört haben will, so dass wir im Grunde drei Zeit- und Raumebenen vor uns haben. Dabei wird auf der dritten und zeitlich letzten Ebene, die im Roman erst gegen Ende aufzutauchen beginnt, die Identifikationsmöglichkeit dieses Ich mit Chateaubriand angeboten. Mit Hilfe dieses Kunstgriffs wird die gesamte Geschichte an die Amerikareise des noch jungen französischen Schriftstellers angebunden.

Damit sind die Unterschiede zu Paul et Virginie auf der narratologischen oder erzähltechnischen Ebene klar. Doch ähnlich wie bei Bernardin de Saint-Pierre haben wir es mit einer in die Kolonialgebiete verlagerten „histoire“ $\mathrm{zu}$ tun, hier nun freilich in ein Nordamerika, in dem die Indianer nicht nur in wechselseitigem Kampfe liegen, sondern sich auch der vorrückenden Europäer und nicht zuletzt auch der christlichen Missionare zu erwehren haben. Immer stärker engt diese 
letztlich siegreiche Zivilisation den Bewegungsspielraum der nomadisierenden indigenen Bevölkerung ein, von der am Ende nur noch wenige isolierte Gruppen, die im Text als „Horden“ erscheinen, übrig bleiben. Es ist, wenn Sie mir diese Bemerkung gestatten, nur noch ein kleiner Schritt bis zur Reduktion der eigentlichen amerikanischen Urbevölkerung auf einige auch heute noch immer stärker beschnittene und eingeengte Reservate, welche ein mahnendes Beispiel für die desaströsen und anhaltenden Folgen fehlender Integration und rassistischer Segregation bestimmter Bevölkerungssegmente in den Vereinigten Staaten von Amerika darstellen. Doch zurück zu Atala!

Das erzählerische Zentrum des Romans wird wiederum von einer Liebesgeschichte gebildet, wobei wir nunmehr einen leibhaftigen Indianer vor uns haben, eben Chactas, der im Grunde den letzten Überlebenden eines untergegangenen Indianerstammes darstellt. Er verdankt sein Leben einem Spanier namens López, der ihn mit äußerster Fürsorge behandelte, ihn mit dem Christentum, aber auch der heidnischen Antike vertraut machte und zwar in San Agustín, dem jetzigen St. Augustin, wo Sie noch heute den berühmten Jungbrunnen, den Quell der ewigen Jugend finden. Wo einst die Spanier nach jener Quelle suchten, welche den aus ihr Trinkenden eine nach antiker Weissagung ewige Jugend verleiht, können Sie heutzutage einen etwas kitschigen Mechanismus bewundern, wo ein Indianer einem rüstigen und gerüsteten Spanier in einem Plastikbecher etwas aus diesem vermeintlichen Jungbrunnen zu trinken gibt. Doch nicht alle Indianer sind den Weißen so treu zu Diensten.

Denn der junge Chactas beschließt, weder zum Christentum überzutreten noch sich der europäischen Zivilisation anzunähern, sondern wieder in die Wälder zurückzukehren, aus denen er kam. Für dieses Leben aber ist er nicht mehr gut vorbereitet, so dass ihn - wie zu erwarten war - bald schon andere Indianer vom Stamm der Muscogulgen gefangen nehmen. Sie wollen den armen Chactas als Gefangenen einer rituellen Opferung zuführen. Vor diesem Ritual zum Wohle des siegreichen Stammes aber errettet ihn die schöne Atala, deren ersten Auftritt wir bereits gesehen haben - und es sollte nicht bei diesem einen Rettungsversuch bleiben. Nun frage ich Sie: Wären Sie Chactas und wären gerade vor dem sicheren Tod errettet, würden Sie sich da nicht auch in die himmlische Atala verlieben?

Doch Chactas war nicht mehr für das Leben in der Wildnis vorbereitet. Nach all den Jahren in der Zivilisation der Europäer kann dies nicht überraschen: Chactas ist längst zu einem kulturellen Mestizen geworden, wie wir an einer Vielzahl von Stellen im Roman bemerken. Kurz vor dessen emotionalem Höhepunkt, den wir keine Angst! - nicht verpassen werden, enthüllt sich dem staunenden Indianer die Tatsache, dass seine von ihm angebetete Atala ihrerseits eine Mestizin ist, und dies ebenso im ethnischen wie im kulturellen Sinne. Neben ihrer genealogischen 
Herkunft, über die wir schon sprachen, gilt dies vor allem für den kulturellen Bereich, wobei auf dieser Ebene deutlich das europäische Erbe dominiert. Für Chateaubriand war dieses europäische „Patrimoine“ vor allem das Christentum.

Nun, wir hatten diese Zugehörigkeit zum christlichen Glauben ja bereits am Kreuz auf Atalas Brust gesehen - denn ein Kreuz in der Wildnis zu tragen ist etwas anderes als das Kreuz heute als schmückendes und glitzerndes Objekt zu nutzen. Für Atala dient dieses Zeichen nicht dazu sich aufzuhübschen. Doch die kulturelle Zugehörigkeit zum Christentum ist mit ihrem biologischen Mestizentum aufs Engste verbunden. Sie ist die Frucht eines Fehltritts, einer illegitimen und unehelichen Liebesbeziehung, weil sich ihre Mutter Simaghan einmal eine Liebschaft geleistet hatte: Sie ahnen es, just mit jenem Spanier López - die Welt ist klein -, den wir bereits als Chactas’ Gönner kennenlernen durften!

Chactas erfährt von dieser Geschichte, als sich die beiden ,Wilden` längst auf ihrer zweiten Ausreistour befinden, denn er wurde ja bekanntlich erneut gefangengenommen und sollte nun auch tatsächlich hingerichtet werden. Doch gelingt ihm dank Atalas tatkräftiger Hilfe ein zweites Mal die Flucht. Eine lange Odyssee durch den Urwald beginnt - Szenen, die ihre Wirkung auf Alexander von Humboldt nicht verfehlt haben dürften, auch mit Blick auf dessen in die dritte Ausgabe seiner Ansichten der Natur aufgenommenen Text von 1849, in welchem Humboldt die nächtlichen Tiergeräusche im Urwald portraitierte. ${ }^{7}$

Aber auch andere Schriftsteller ließen sich - wie wir noch sehen werden - von diesem Herumirren in der Wüste beeindrucken: nicht zuletzt der argentinische Romantiker Esteban Echeverría oder der Kolumbianer Jorge Isaacs, mit deren Romanen wir uns noch beschäftigen. Vielfältig sind die Rezeptionsweisen dieses Romans und variationsreich die von ihm geprägten Texte auf der europäischen wie der amerikanischen Seite des Atlantik. Doch kehren wir noch einmal kurz auf die Inhalts- und Handlungsebene von Chateaubriands Atala zurück!

Die beiden Verliebten irren also durch den Urwald; und just in diesen tiefen Wäldern kommt es nun - oh heilige Liebe! - zu einer Szene der (Beinahe-) Vereinigung, die weitaus weiter ging als die Liebeleien in Bernardin de Saint-Pierres Paul et Virginie. Ich möchte Ihnen gerne die gesamte Passage einschließlich ihres eher abrupten Endes vor Augen führen. Dazu aber müssen wir vorab schon wissen, dass Atalas Mutter aufgrund ihres Fehltritts ihre Tochter unerhörterweise schwören ließ, gleichsam ihren eigenen Fehler auszubügeln und sich niemals einem

7 Vgl. hierzu Ette, Ottmar: Motion, Emotion, Musik. Alexander von Humboldts experimentelle Klangtexte. In: Colloquium Helveticum - Schweizer Hefte für Allgemeine und Vergleichende Literaturwissenschaft (Bielefeld) 48 (2019) (Sondernummer „Musik und Emotionen in der Literatur“, hg. von Corinne Fournier Kiss), S. 27-52. 
Manne hinzugeben. Ein Schwur, den die liebreizende Atala allen Anfechtungen zum Trotz auch bis zu diesem Zeitpunkt der Mutter treu gehalten hatte. Nun aber kommt es zur höchsten Versuchung der hübschen Mestizin im Urwald.

Denn soeben haben Atala und Chactas zu ihrer Verblüffung festgestellt, dass sie ihr Leben gleichermaßen dem selben Mann verdanken, dem Spanier López. Und so gerät ihre Liebesbeziehung fast in eine geschwisterliche und damit zugleich auch inzestuöse Schieflage, wie sie im 19. Jahrhundert im Zeichen der Romantik besonders attraktiv werden sollte. Doch kann es in letzter Instanz nicht zum Inzest kommen, sind unsere beiden jungen ,Wilden' doch nur auf einer übertragenen Ebene als López' Kinder anzusehen. Diese Entdeckung, die natürlich mit der Entdeckungsgeschichte des gesamten Kontinents zu tun hat, konnte jedoch ihre letzten Widerstände gegen die Realisierung einer Liebesbeziehung brechen:

Diese brüderliche Freundschaft, welche nun hinzukam, war zu viel für unsere Herzen, verband sich doch ihre Liebe nun mit unserer Liebe. Fortan sollten die inneren Kämpfe Atalas unnütz werden: Vergeblich fühlte ich, wie sie eine Hand auf ihren Busen legte und eine außerordentliche Bewegung machte; schon hatte ich sie ergriffen, schon war ich von ihrem Atem trunken, schon hatte ich die ganze Magie der Liebe auf ihren Lippen getrunken. Ich hatte meine Augen im Lichte der Blitze zum Himmel erhoben und hielt in der Gegenwart des Ewigen Gottes meine Gattin in meinen Armen. Welch ein Brautschmuck, der unseres Unglückes und der Größe unserer Liebe würdig war: Oh großartige Urwälder, die ihr Eure Lianen und Eure Kuppeln wie die Vorhänge und den Himmel unseres Bettes bewegt, oh ihr brennenden Kiefern, die ihr die Fackeln unseres Ehevollzuges hieltet, oh über die Ufer getretener Fluss, ihr brüllenden Berge, oh schreckliche und sublime Natur, wart ihr denn nichts als die Mittel, dazu bereitet, uns zu täuschen, und konntet Ihr nicht einen einzigen Augenblick lang in Euren rätselhaften Schrecknissen das Glück eines Mannes verbergen!

Atala setzte bloß noch einen schwachen Widerstand entgegen; ich berührte den Augenblick des Glückes, als plötzlich ein ungestümer Blitz, gefolgt von einem krachenden Einschlag, die Dichte der Schatten furchte, den Urwald mit Schwefelgeruch und Leuchten füllte und einen Baum zu unseren Füßen zerfetzte. Wir flohen. Oh Überraschung! ... In der nachfolgenden Stille hörten wir den Klang einer Glocke! Wir verstummten beide und lauschten diesem in der Menschenleere so seltsamen Geräusch. Augenblicklich bellt in der Ferne ein Hund; er kommt näher, vervielfacht sein Geschrei, kommt heran, zu unseren Füßen rast er vor Freude; ein alter Einsiedler, eine kleine Laterne in der Hand, folgt ihm durch die Finsternisse des Urwalds. „Gebenedeit sei die Vorsehung“, rief er aus, als er uns erblickte. „Lange schon suche ich nach Euch!“8

Diese schöne und literarisch sehr präzise konstruierte Passage gibt im Grunde recht genau den Untertitel des Kurzromans wieder. Denn in der Tat sind die beiden ,Wilden“ und Liebenden hier im „désert“, auch wenn sie mitten in einem

8 Chateaubriand: Atala, S. $61 \mathrm{f}$. 
subtropischen Urwald stehen. Denn mit „désert“ ist - wie wir schon wissen - im damaligen Sprachgebrauch eine menschenleere Region gemeint und nicht notwendigerweise das, was wir unter einer Wüste verstehen. Man sollte diese „forêts“ daher auch eher als eine Art Urwald bezeichnen, auch wenn wir es ,nur' mit subtropischen Pflanzenformationen zu tun haben. Soviel vielleicht zum geographischen Setting und zur Landschaft, die sich Chateaubriand für seine Lesenden wie seine Liebenden ausgedacht hat!

Inmitten dieser Landschaft kommt es nun in der aufgeheizten und mehr oder minder tropischen Atmosphäre der Wälder zur lange sich schon andeutenden Vereinigung der beiden Liebenden, gleichsam zu einer sich vollziehenden erotischen Entladung - und deren Verhinderung in allerletzter Minute. Die Entwicklung hin zur sexuellen Vereinigung ist als körperlich-leibhaftige Entladung wahrlich eingebettet in eine tropische Seelen-Natur, welche die Atmosphäre in ungeheurem Maße erotisch auflädt, zugleich aber die Seelenzustände der beiden Liebenden spiegelt. Der Indianer Chactas kann sich jener Magie der Liebe und der Ausstrahlungskraft, die vom Körper-Leib der jungen Mestizin auf ihn ausgeht, nicht mehr entziehen: Er wird zum lustvollen Opfer dieser Sinnlichkeit und seiner Sinne.

Die von Chateaubriand so meisterhaft geschilderte Natur ist eine Natur, die folglich der erotisch aufgeladenen Stimmung zwischen beiden Liebenden entspricht. Daher wird sie zum Bett, in dem sich die Vereinigung vollziehen kann und das Jungfernhäutchen, das hier als frz. „hymen“ nur im übertragenen Sinne erscheint, ins Zentrum der gesamten Szenerie gerückt. Denn Atala ist ihrem Schwure gemäß noch unberührt und jungfräulich. Doch der Vollzug einer ehelichen Vereinigung - auf frz. ebenfalls „hymen“ - steht unmittelbar bevor. Daher ist auch nicht mehr von Braut, sondern von Gattin die Rede.

Die literarisch derart beschriebene Natur stellt einen Gleichklang zwischen Individuum und Umwelt her, sie ist Korrespondenz-Natur. Angesichts der Aktivität des Mannes, der die körperlichen Attribute der Frau gleichsam verschlingt, in sich einsaugt und sich einverleibt bis zur Trunkenheit, wird Atalas Widerstand, die den gegenüber ihrer Mutter geleisteten Schwur keineswegs vergisst, immer schwächer. Sie wird später sagen, dass sie fast schon ihre Mutter in den Abgrund gestürzt habe, der sich durch den unmenschlichen Schwur, der die eigene vermeintliche ,Schuld' mit der Sühne der Tochter zu begleichen sucht, unter ihr auftat.

Auch die Familienbezeichnungen sind aufschlussreich. Die brüderlich beobachtete Schwester, die „sœur“, ist fast schon zur Gattin, zur „épouse“, geworden, die mit ihrem Mann ihre Augen gen Himmel hebt, von wo aus ein deftiges Donnerwetter mit Blitzeinschlag und allem Drum und Dran herniedergeht. Das ist in der Literaturgeschichte nichts Neues, denn das Gewitter zeigt literarisch oftmals den Zeitpunkt einer körperlichen Vereinigung an, ähnlich wie etwa das Feuer- 
werk, das sich just in derselben Art und Weise psychoanalytisch deuten lässt. Die ganze Natur wird zu einer einzigen „couche“, zu einem großen gigantischen Himmelbett einer Liebesnacht inmitten der Natur, wo sich die natürlichen Triebe der Liebe ihren Weg bahnen und - so scheint es - durch nichts aufzuhalten sind. Die Natur wird dadurch „affreuse“ und „sublime“ zugleich, sie ist eine widersprüchliche und schrecklich-erhabene Natur, weil sie zum einen den Liebenden ihre Freiheit gibt, sie zum anderen aber gerade gegen die Gesetze der christlichen Religion und Zivilisation verstoßen lässt. Diese Gesetze der Menschen machen die Zivilisation, die Kultur aus, und sie werden im Kontext des Génie du Christianisme selbstverständlich mit dem Christentum an höchster Stelle in eins gesetzt.

Auch die Verwendung der Zeiten ist in der obigen Passage sehr bemerkenswert. Denn just an dieser Stelle können Sie beobachten, wie ein Imparfait von einem Passé simple unterbrochen, überlagert, in den Hintergrund gedrängt wird; denn gerade, als die Vereinigung der beiden Liebenden unmittelbar bevorsteht, fährt von oben - wie ein Deus ex machina - ein Blitz hernieder und fällt einen der Urwaldriesen, unterbricht damit das Liebesspiel der beiden ,Wilden“. Das Fällen und Spalten dieses Baumes, der zu Boden gestreckt wird, ist psychoanalytisch ohne weiteres deutbar als gleichsam göttliche Kastration des armen Indianers, der so kurz vor dem Genuss der Liebeswonnen gestanden hatte. Armer Chactas, wie kam der Blitz für Dich doch zur Unzeit!

In der Tat ist diese göttliche Kastration nachhaltig, denn Chactas wird sein Leben lang nicht mehr in den Genuss der Liebe kommen. Als Blinder wird er später zudem nicht mehr unter der Concupiscencia oculorum leiden, wird also gegen alle Begehrlichkeiten versichert sein. Wer noch daran gezweifelt hätte, dass hier ein Gott - natürlich der christliche Gott - von oben eingegriffen hat, der wird eines besseren belehrt, denn bald schon erscheint der Solitär, der christliche Einsiedler, der Mönch als christlicher Retter in höchster Not. Er ist der Vertreter der „Providence“, der katholischen Vorsehung, auch wenn ihm ein Hündchen als Symbol des Gehorsams vorausgeht. Doch auch dieses freudig bellende Wesen ist keineswegs unschuldig, so wie Tiere im Text stets eine Bedeutung haben: Denn das Hündchen, das sollten wir nicht vergessen, pflegt in derlei Situationen nicht selten als Höllenhund aufzutreten. Auch davon weiß der Text, wie wir gleich sehen werden, $\mathrm{zu}$ berichten.

An die Stelle der Geräusche von Natur und Sinnlichkeit tritt zunächst das Schweigen, eine Stille, dann der Klang einer Glocke, des christlichen Klanges schlechthin. Hier erreichen wir die Weggabelung oder Kreuzung zwischen Natur und Kultur: Die Natur wird in ihre Schranken gewiesen, die Kultur bahnt sich ihren Weg - und dafür gilt es für die beiden,Wilden“ einen Preis zu entrichten, der sehr hoch ist. Der grundsätzliche, die gesamte Geschichte des Abendlandes und 
zutiefst auch die jüdisch-christliche Welt prägende Gegensatz zwischen Natur und Kultur charakterisiert in der Folge das Zerrissen-Sein des Menschen, der zwar der Natur in gewisser Weise zugehört, sich aber gerade aus dem Naturzustand befreit, um überhaupt höherer Werte teilhaftig werden zu können.

Ich darf an dieser Stelle unserer Argumentation kurz einflechten, dass ein solcher Gegensatz durchaus kulturell bedingt ist. Es gibt Kulturen wie die altjapanische oder altchinesische, welche ihn nicht kennen und auch kein eigenes Wort etwa für „Natur“ besitzen, so dass sie es später der abendländischen Kultur, den westlichen Sprachen, entlehnen mussten. Wir selbst können an unserem eigenen Körper sehen, dass sich im Menschen Natur und Kultur ohne irgendwelche Grenzziehungen überschneiden. Wenn Sie in dieser Vorlesung plötzlich Kopfweh bekommen, so könnte dies ebenso physische wie psychische, ebenso biologische wie psychosoziale Gründe haben. Sind es die Inhalte der Vorlesung oder Ihre verkrampfte Körperhaltung, die dieses Kopfweh auslösen? Ich will mich da nicht einmischen! Sie könnten, falls sich das Ganze zu einer veritablen Migräne auswächst, entweder zu einem Schulmediziner und zu einer Orthopädin oder zu einem Psychologen, vielleicht auch zu einer Psychoanalytikerin gehen, um ihren Beschwerden auf die Schliche zu kommen. Was ich Ihnen damit zeigen will, ist schlicht die simple Tatsache, dass wir als Menschen voll und ganz im Überschneidungsbereich von Kultur und Natur stehen und es per se keine Gründe dafür gibt, beide Bereiche - wie in unserer Religion, aber auch unseren Wissenschaften - strikt voneinander zu trennen. Wie die Geschichte der unterschiedlichsten Kulturen auf diesem Planeten zeigt, ist die Trennung der Natur von der Kultur eine rein kulturelle Setzung.

Dass der zivilisatorische Prozess mit dieser klaren Trennung unter starken Verlusten sowie unter großem Verzicht erkauft wurde und wird, lässt sich an dieser Stelle von Chateaubriands Atala hervorragend zeigen. Denn die Rettung durch das Christentum bringt nicht etwa die Glückseligkeit schlechthin, sie führt gerade nicht zu einem Glück ohne Grenzen, sondern führt einen geschichtlichen und zivilisatorischen Prozess noch einmal vor Augen, an dessen Ende sich letztlich eine zerrissene Menschheit befindet. Es handelt sich um eine Menschheit, die am Abgrund steht und in diesem zivilisatorischen Prozess vor allem mit dem eigenen Leben, dem eigenen Körper-Leib die Zeche zahlen muss. Es ist eine schöne Mär, ein hübsches Märchen, dass ein höherer Grad an Zivilisation auch höhere Grade an Glück mit sich bringt, so wie es ein Werbemärchen ist, dass mehr Konsum zu immer mehr Zufriedenheit, ja Glückseligkeit führt. Und da haben wir nun die beiden Liebenden in der Einsamkeit menschenleerer Regionen, in denen zu ihrem Unglück ein christlicher Einsiedler lebt: Die beiden liebenden ,Wilden“ oder ,wilden“ Liebenden können nicht zusammenfinden, und sie können auch nicht mehr voneinander lassen. Damit aber ist der Weg gebahnt 
für jene Krankheit des Jahrhunderts, eben die Melancholie, mit der wir uns noch beschäftigen wollen.

Lassen Sie mich noch kurz auf einige zusätzliche Aspekte zu sprechen kommen! Symbolträchtig ist - wie wir schon sahen - der krachende Einschlag des hell den Urwald ausleuchtenden Blitzes in das Penis-Symbol des Baumes, der dann auch sofort zu Boden fällt. Die gesamte Struktur des Textes ist erotisiert, erotisch semantisiert, so dass der ganze Wald mit seinen Bäumen, Ästen und Lianen ein erotisches Gewebe bildet, wobei gerade auch den Verbindungsstücken zwischen zwei Elementen - etwa den Lianen - eine große Bedeutung zukommt. Die Liebenden sind gleichsam eingebettet in eine Korrespondenz-Natur, sind Teil des Kosmos und einer Natur, mit der sie eins werden und in ihrer eigenen geschlechtlichen Eins-Werdung zusätzlich noch ineinander verschmelzen.

Genau dieser Verschmelzungsprozess wird durch den Blitzeinschlag gespalten; und es tritt nun der zivilisatorische Prozess mit seinen spezifischen Kosten auf den Plan. Bemerkenswert ist, dass in der oben zitierten Passage sich Atala zunächst an den Busen greift, also eigentlich an den Ort der Verlockung, aber eben noch mehr an den Ort des Kreuzes, das sie nun kaum noch aufrecht zu halten vermag. An diesem Herzpunkt treffen Natur und Kultur unmittelbar aufeinander; und zugleich ist jetzt jener der Mutter einst geleistete Schwur in Gefahr. Daher ist dem Blitzeinschlag auch ein wenig „soufre“, ein wenig Schwefel beigemischt, denn um ein Haar wäre ja die junge Frau dem Teufel verfallen - der ja bekanntlich nach Schwefel riecht. Sie merken, dass von hier aus auch ein Weg zum Höllenhündchen führt, das sich freilich dann als freundliches und treues Tierchen erweist, welches innerhalb einer anderen, dominikanischen Tradition nun für Treue und Gehorsam steht. Wir wissen nicht, ob der Einsiedler und Mönch Dominikaner war, doch betrachteten sich diese „domini canes“ als „Hunde des Herrn“. Jedenfalls bellt das Hündchen ganz freudig, klar: Es hat zumindest eine Seele für das Christentum, wenn auch nicht für das eigene Glück gerettet!

Das Christentum ist die Leitlinie dieses Prozesses, dessen Kosten beträchtlich sind, wie wir sahen. Hier gibt es zahlreiche Berührungspunkte oder gar Parallelen mit Jean-Jacques Rousseau, vertrat dieser doch in seinem Discours sur l'origine de l'inégalité parmi les hommes doch die Ansicht, dass die Menschen von Geburt an gut sind und erst durch den Vergesellschaftungsprozess depraviert und zunehmend moralisch schlechter werden. Der zivilisatorische Prozess erscheint und verkörpert sich in der Figur des Einsiedlers, der im Übrigen sehr wohl weiß um dessen hohe Kosten. Dies wird sich auch in der Szene von Atalas Agonie und dem sich anschließenden Reinigungsprozess zeigen, den wir uns noch näher ansehen werden.

Ich möchte Ihnen nun nicht die verschiedenen Peripetien des weiteren Verlaufs der Geschichte erzählen, in der uns der Priester als grundguter Mensch vor- 
gestellt wird, der es auf das Wohl und Seelenheil der Indianer abgesehen hat. Seine Aufgabe ist gleichsam zivilisatorisch: Er versucht vorübergehend erfolgreich - er wird am Ende von anderen Indianern umgebracht werden -, nomadisierende Indigene zum sesshaften Leben und zugleich zur Verehrung des Christengottes zu bringen. All dies spielt sich unweit der Ufer des Mississippi ab, in jener Region, die Chateaubriand wohl aus eigener Erfahrung kannte.

Nachdem wir im ersten Teil des Romans viel über angebliche, aber von Chateaubriand herbeigeflunkerte Sitten und Gebräuche der ,wilden“ Indianer, die Chactas töten wollten, erfahren haben - darunter übrigens auch allerlei anmutigerotische Tänze barbusiger Jungfrauen -, lernen wir im zweiten Teil einiges über das Leben der dem Christentum sich zuwendenden indianischen Stämme, die zunehmend sesshaft geworden sind. Die Darstellung dieser Entwicklungen wäre eine Reihe eigener Reflexionen wert, was hier aber unterbleiben soll, da wir nun die Situation der Liebenden mit ihrem zwischen Natur und Kultur gespaltenen Bewusstsein noch etwas näher ausleuchten sollten.

Im Grunde ist das Christentum - wie Reinhold Grimm in seiner schönen Studie zu François-René de Chateaubriand betonte ${ }^{9}$ - zugleich der Verursacher der grundlegenden Spaltung des Menschen und das Heilmittel, das die Menschen letztlich wieder in einer höheren Einheit zu einem Ganzen zusammenführen soll. Das Christentum ist in diesem Sinne ein Pharmakon, ein Heilmittel, das zugleich positive und negative Wirkungen hat, so wie Sie bei jedem Medikament je nach Dosierung positive, aber auch negative Wirkungen und Nebenwirkungen in Rechnung stellen müssen. Der christliche Glaube tritt in Le Génie du Christianisme ungezählte Male in dieser doppelten Rolle auf; und auch in Atala sehen wir ihn just in dieser gesellschaftsbildenden, gesellschaftsgründenden und zugleich gesellschaftsgefährdenden sowie heilenden Funktion.

Die junge, unschuldige Atala jedenfalls weiß weder ein noch aus: Auf der einen Seite steht der christliche Schwur ihrer Mutter, verkörpert gleichsam durch das große güldene Kreuz, das ihre Brüste beschützt, und damit ein christliches Verbot. Nicht umsonst hatte es bei den beiden jungen ,Wilden' im Paradies geheißen, dass sie angesichts des Klanges der Glocke völlig „interdits“ waren. Denn die Früchte im Garten Eden sind ihnen untersagt und verboten. Auf der anderen Seite weiß Atala sich unerschütterlich in ihrer großen, wir dürfen sagen: romantischen Liebe zum jungen Indianer Chactas.

9 Vgl. Grimm, Reinhold R.: Wendezeiten. Revolution und Poesie: François-René de Chateaubriand. In: Plocher, Hanspeter / Kuhnle, Till R. / Malinowski, Bernadette (Hg.): Esprit civique und Engagement. Festschrift für Henning Krauß zum 60. Geburtstag. Tübingen: Stauffenburg Verlag 2003, S. 171-186. 
So tut sie also einen Schritt mehr als Virginie und rettet sich aus diesem Dilemma, dieser verzweifelten Situation durch einen wenig christlichen Selbstmord. Zu spät erfährt sie, dass das Christentum einen Ausweg für ihre nur scheinbar ausweglose Situation geboten hätte, hört sie doch vom christlichen Einsiedler noch, dass ein Bischof sie von der Last des Schwures hätte befreien können. Dieses Wissen verstärkt noch die Tragik ihrer Lage. Denn sie hat bereits ein tödliches Gift zu sich genommen, das seine Wirkung tut: Alle Rettungsversuche kommen zu spät. Diese in der französischen Literatur berühmte Sterbeszene, die unzähligen Literaten und Künstlern später als Vorlage dienen sollte, will ich Ihnen verbunden mit der nachfolgenden Apotheose der schönen und ihrem Schwure bis in den Tod hinein treuen Mestizin nicht vorenthalten. Es ist eine längere, präzise literarisch ausgefeilte Passage:

Kaum hat er diese Worte gesprochen, da zwingt mich eine übernatürliche Kraft, am Fuße des Bettes von Atala auf meine Knie zu fallen und den Kopf zu senken. Der Priester öffnet einen geheimen Ort, wo eine goldene Urne eingeschlossen war, welche ein seidener Schleier bedeckte; er verfällt in Ehrerbietung und tiefste Anbetung. Die Grotte schien plötzlich voller Licht zu sein; man hörte in den Lüften die Worte der Engel und das Erklingen der himmlischen Harfen; und als der Einsiedler das geheiligte Behältnis aus dem Tabernakel zog, glaubte ich, Gott selbst aus der Seite des Berges hervortreten zu sehen.

Der Priester öffnete den Kelch; nahm zwischen beiden Fingern eine Hostie heraus, die so weiß wie der Schnee war, und näherte sich Atala, indem er mysteriöse Worte aussprach. Diese Heilige hatte in Ekstase ihre Augen zum Himmel erhoben. All ihre Schmerzen schienen aufgehoben, ihr ganzes Leben versammelte sich auf ihrem Mund; Leicht öffneten sich ihre Lippen und suchten respektvoll den in einem mystischen Brot verborgenen Gott. Hernach taucht der göttliche Greis ein wenig Baumwolle in ein geweihtes Öl und bestreicht damit die Wangen von Atala, betrachtet einen Augenblick lang das sterbende Mädchen, und plötzlich entgleiten ihm diese starken Worte: „Steigen Sie auf, oh christliche Seele: Vereinigen Sie sich wieder mit Ihrem Schöpfer!“ Ich hob nun meinen niedergeschlagenen Kopf und rief beim Anblick des Behältnisses, in dem sich das heilige Öl befand, aus: „Mein Vater, wird dieses Heilmittel Atala wieder das Leben zurückgeben?“ „Ja, mein Sohn“, sagte der Greis, indem er in meine Arme fiel: „Das ewige Leben!“ Atala hatte ihren letzten Atemzug getan! [...]

Ihre Lippen waren einer Rosenknospe gleich, die nach zwei Morgen gepflückt, und schienen zu schmachten und zu lächeln. Auf ihren Wangen von strahlendem Weiß zeichneten sich einige blaue Venen ab. Ihre schönen Augen waren geschlossen, ihre kleinen Füßchen lagen nebeneinander und ihre Alabasterhände pressten ein Kruzifix aus Ebenholz auf ihr Herz; das Skapuliertuch ihrer Gelübde war an ihren Hals gerutscht. Sie schien vom Engel der Melancholie verzaubert und durch den doppelten Schlaf der Unschuld und des Grabes noch verschönt. Nichts Himmlischeres habe ich jemals gesehen. Wer auch immer nicht wüsste, dass dieses Mädchen sich einst am Lichte erfreut, hätte sie für die Statue der schlafenden Jungfräulichkeit gehalten. ${ }^{10}$

10 Chateaubriand: Atala, S. 94-98. 


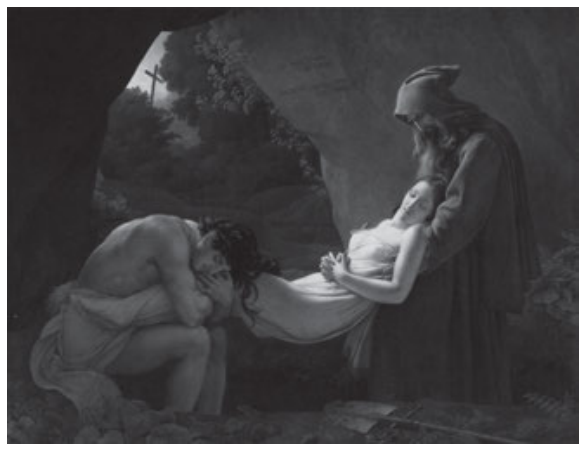

Abb. 19: „Atala au tombeau, dit aussi Funérailles d'Atala“, Öl auf Leinwand von AnneLouis Girodet de Roussy-Trioson, 1808.

An dieser literarisch ausgearbeiteten Passage sollten sich im weiteren Verlauf der Literaturgeschichte des 19. Jahrhunderts noch zahlreiche Schriftstellerinnen und Schriftsteller orientieren, die ihre Heldinnen einen romantischen Gifttod sterben lassen wollten. Der berühmteste unter ihnen war sicherlich Gustave Flaubert, der seine Emma Bovary ebenfalls einen Freitod mit Gift sterben ließ, wobei er die letzten Zuckungen seiner Heldin noch mit den letzten Segnungen der Kirche in ein ironisches Kontrastlicht setzte. Bei Chateaubriand fehlt diese ironische Beziehung allerdings auf ganzer Linie: Der Verfasser von Le Génie du Christianisme war auch in seinem Kurzroman bemüht, in der mit zahlreichen ästhetischen Details ausgeschmückten Szenerie die heil- und segenbringende Macht der Kirche in all ihrer Schönheit erstrahlen zu lassen.

Die bezaubernde und verzauberte Atala wird in diesem Zitat Stück für Stück stillgestellt: Aus der lebendigen jungen Frau wird so etwas wie eine Statue der Jungfräulichkeit, die in ihrer steinernen Stille verharrt. Auf der christlich-religiösen beziehungsweise ideologischen Ebene ist die Rede davon, eine Ganzheit des Menschen wie aller menschlichen Kultur durch das Christentum wiederherzustellen. Diese segensreiche Kraft sollte laut Chateaubriand vom Christentum als Weltreligion ausgehen - und zwar zum Wohle aller Menschen auf diesem Planeten. Außerdem wurde selbstverständlich von ihm das christliche Paradoxon schlechthin zentralgestellt: jenes nämlich, das den Tod zum wahren Leben erklärt und das Ewige Leben dem irdischen Leben bei weitem vorzieht. Der Indianer Chactas kann all dies in der Szenerie rund um den Tod seiner Geliebten noch nicht begreifen, zeigt in seinen Reflexionen aber, dass er es als alter Mann längst begriffen hat. Nicht umsonst wurde er in die Arme der Kirche - in Gestalt des christlichen Einsiedlers - tränenreich, aber zuversichtlich aufgenommen.

In dieser dem Sterben Atalas gewidmeten Passage wird es vorgeführt, das Ewige Leben in seinem Beginn, am Ende eines individuellen Lebens. Die Tatsache, dass Selbstmörderinnen und Selbstmörder aus dem Kreise der christlich Lebenden und Sterbenden bewusst ausgeschlossen wurden, wird hier geflissent- 
lich übergangen, was wiederum zeigt, dass es Chateaubriand keineswegs um eine von Kirchenrecht und Dogma abgesicherte Rechtsposition ging. Dem jungen französischen Schriftsteller war es um die Schönheit, die ästhetische Dimension der letztlich zur bildhübschen Statue erstarrenden Frau zu tun, die nicht mehr als Individuum zählt, sondern zur skulpturalen Verkörperung christlich-weiblicher Jungfräulichkeit avanciert.

Zugleich wird eine Vielzahl weiterer christlicher und literarischer Dimensionen in diesen Tod Atalas eingeblendet, der auch in der zeitgenössischen Malerei so oft festgehalten wurde. Chateaubriand war dabei in seinen relationalen Verknüpfungen von Atalas Bild mit verschiedensten künstlerischen Traditionen nicht wählerisch. So sind etwa die Bezüge zur spanischen Mystik ganz offenkundig: Die zum Himmel erhobenen Augen machen darauf aufmerksam, dass nicht nur ein ewiges himmlisches Leben an die Stelle des irdischen Lebens rückt, sondern dass auch ein himmlischer Bräutigam an die Stelle des irdischen Bräutigams tritt. Die Aufnahme der Hostie, die Einverleibung des heiligen Leibes, deutet diese Bewegung unverkennbar an. Das Schließen der Augen - und damit rein etymologisch die Bedeutung von „Mystik“ - führt diesen Transformationsprozess zu einem guten, will sagen christlichen Ende.

Dabei ist diese Liebe zum himmlischen Bräutigam, die in der Mystik stets eine wichtige, ja oftmals zentrale Rolle spielte, keine Liebe, welche die Jungfräulichkeit der Liebenden in Gefahr bringen könnte. In der späten Romantik wird sie desakralisiert und von ihren christlichen Attributen stärker losgelöst, übernimmt aber mehr denn je zentrale Funktionen für den Handlungsgang wie auch die sich überkreuzenden Bedeutungsebenen ebenso in Romanen und Erzählungen wie in Gedichten oder Theaterstücken. Wir sollten diese religiöse christliche Herkunft als einen Strang im Gedächtnis behalten, der zusammen mit der aus arabischen Einflüssen hervorgegangenen Liebeskonzeption die Tradition der romantischen Liebe im Abendland prägt. ${ }^{11}$

In Chateaubriands Atala werden all diese Liebesbewegungen buchstäblich fest- und stillgestellt: Nicht umsonst wird Atala unmittelbar nach ihrem Tod ihrem frustrierten Liebhaber als die Statue der Jungfräulichkeit schlechthin erscheinen. Sie ist ihm als Kunst, als ästhetisches Artefakt gänzlich entrückt. So wird sie zu einer zweiten Virginie, die ebenfalls ihre Augen im Angesicht des Todes gen Himmel hob, nach Rettung im christlichen Jenseits suchend. Doch ist sie eine Virginie in der Überbietungsstrategie: Denn sie übertrumpft Bernardin de Saint-Pierres Virginie, weil sie sich letztlich zum Selbstmord bekennt, weil es

11 Vgl. hierzu Rougemont, Denis de: L'Amour et l'Occident. Paris 1939. Vgl. hierzu ausführlich Ette, Ottmar: LiebeLesen, S. 135-161. 
um ein Haar zum Liebesakt kommt, der nur vom findigen Hündchen verhindert wird. Und sie überbietet Virginie, weil sie sich nicht nur selbst entleibt, sondern weil sie am Ende zu einem Kunstwerk wird, das - von Männerhand gezeichnet, gemalt oder gemeißelt - zu einer Repräsentation eines weiblichen Idealbildes wird.

Die Mestizin wurde ins Christentum aufgenommen, ja wird zu einer Heiligen im Schoße dieses Christentums, dessen universalistische, weltumspannende Ansprüche sie vor Augen führt. Atala gerät dadurch zur romantischen Heldin schlechthin, zum Modell all jener ihr nachgebildeten, schönen Protagonistinnen, die sich ihrer Verfahren dann freilich in desakralisierender Geste bedienen. Das Christentum bringt Atala zwar den Tod, wie diese Sterbeszene zweifellos zeigt; es bringt ihr aber auch die Rettung und das Ewige Leben.

Wir sollten dabei nicht vergessen, dass Atala nicht nur zur Statue der schlafenden Jungfräulichkeit und Unschuld wird, sondern dass sie zugleich in die Nähe des Engels der Melancholie gerückt wird. Dass an dieser Stelle Chateaubriand bei seinem Lesepublikum fraglos das Wissen voraussetzte, um welchen Engel der Melancholie es sich hierbei handelt, lässt uns keinen Augenblick daran zweifeln, dass der französische Dichter an Albrecht Dürers berühmte Studie Melencolia von 1514 dachte. Dürers Allegorie der Melancholie war in der Tat eines jener großen und großartigen Bildnisse, welche die Romantik und das 19. Jahrhundert wie ein roter, ich müsste besser sagen: wie ein schwarzer Faden durchziehen.

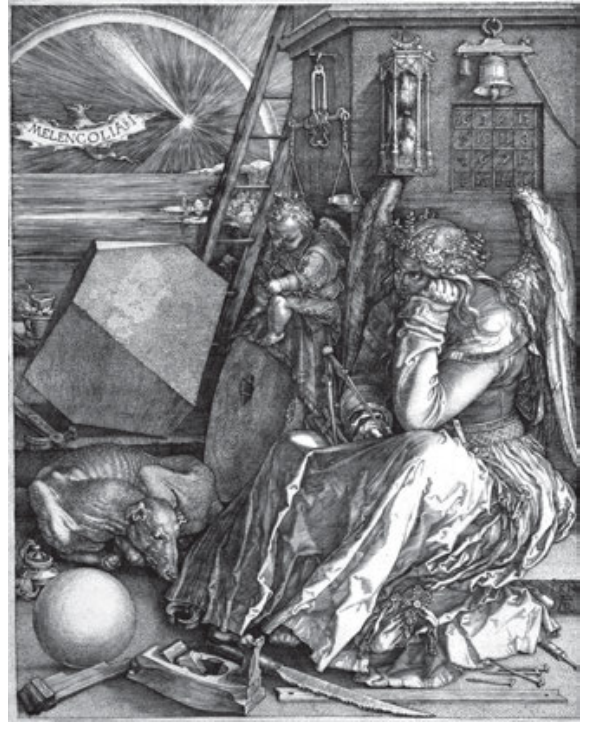

Abb. 20: „Melencolia I“, Stich von Albrecht Dürer, 1514. 
Im Grunde sollten wir an dieser Stelle unserer Vorlesung angekommen eines der berühmtesten Gedichte der Romantik analysieren, das sich justament auf dieses allegorische Bildnis Dürers bezieht, nämlich Gérard de Nervals herausragendes Sonett El Desdichado. Doch wir können uns auch der Problematik der Melancholie überhaupt zuwenden, zu der die aus Bulgarien stammende, aber ihre große Zeit in Paris erlebende Julia Kristeva eine wichtige Studie vorlegte, deren Titel bereits auf Albrecht Dürer, aber auch Nervals Vers vom „soleil noir de la mélancolie“ verweist, der „schwarzen Sonne der Melancholie“. 